\title{
Bilateral Subtalar Dislocation in Gymnast: A Case Report*
}

\author{
Atif Mechchat", Mardy Abdelhak, Mohammed Shimi, Abdelhalim Elibrahimi, Abdelmajid Elmrini \\ Department of Orthopaedic Surgery B4, Hassan II Fez, Morocco. \\ Email: \#atif.mechchat@hotmail.fr, medfes@gmail.com,mdshimi78@gmail.com, halimibahimi@yahoo.fr, traumajid@yahoo.fr
}

Received August 5 ${ }^{\text {th }}$, 2013; revised September $5^{\text {th }}$, 2013; accepted September $21^{\text {st }}, 2013$

Copyright (c) 2013 Atif Mechchat et al. This is an open access article distributed under the Creative Commons Attribution License, which permits unrestricted use, distribution, and reproduction in any medium, provided the original work is properly cited.

\begin{abstract}
Subtalar dislocation is a rare injury in elite athletes. We report an unusual case of simultaneous bilateral subtalar dislocation in an international female athlete competing in gymnastics. These injuries require prompt reduction and immediate immobilisation in a plaster cast for 8 weeks or wire stabilisation after open reduction if an abrupt end to a promising career is to be prevented.
\end{abstract}

Keywords: Subtalar; Dislocation; Bilateral; Gymnast

\section{Introduction}

Subtalar dislocation, also known as peritalar dislocation, refers to the simultaneous dislocation of the distal articulations of the talus at the talocalcaneal and talonavicular joints. It is not a common injury and it accounts for approximately $1 \%$ of all dislocations. Bilatetral subtalar dislocation is rarely reported in the literature. Closed reduction and immobilization remain the treatment of choice. The entrapment of the joint capsule may cause difficulty in closed reduction; hence open reduction may be necessary. This case report presents a bilateral subtalar dislocation in gymnast with an unsuccessful closed reduction of a medial right subtalar dislocation which required an open reduction technique using wire stabilization and the left ankle treated by closed reduction.

\section{Case Report}

A 24-year-old woman, a gymnast athlete, presented with bilateral recurrent ankle sprains for a period of 2 years. The condition had worsened during the previous 6 months and he went to the team physiotherapist for advice. Bilateral instability was found but no preventive treatment was given. The gymnast continued to participate in competitions at an elitist level. While she was doing her choregraphy, she fell after a jump "triple somersaults" and she landed with her left foot on the right one. At department of orthopaedic surgery B4, the examination revealed an inversion deformity of the both ankles (Figure

* Declaration of conflicting interests: The authors declared no conflicts of interest with respect to the authorship and/or publication of this article.

${ }^{\#}$ Corresponding author. 1(a)). The dorsalis pedis pulse was readily palpable and sensation was intact. There was no sign of neurovascular damage. Radiographs confirmed a bilateral medial subtalar dislocation (Figure 1(b)). Under general anaesthesia, only the left ankle was reduced easly but the right ankle needed an open reduction using wire stabilization due to an entrapment of the joint capsule. Both ankles were immobilized in a plaster cast for 8 weeks (Figure 1(c)). Fifteen months later she had no pain. The movements in the subtalar joint were complete. Power in this foot was as good as in the other.

\section{Discussion}

Elite female gymnasts may train on average 5.36 days a week and 5.04 hours a day [1], which exposes them to a high risk of serious injury. Subtalar dislocations in female athletes are not uncommon but bilateral dislocations are very rare and to our knowledge only one case have been described by Mattingly and Sternin 1983 [2]. They reported a case of bilateral subtalar dislocations after trauma.

Bilateral dislocations have been reported with ehlers danlos syndrome [3]. The incidence of subtalar dislocation is 6 to 10 times higher than in females [4].

A subtalar dislocation is rarely seen in sports, though, Grantham [5] reported five cases of subtalar dislocations, of which four had occurred in basketball players. He therefore termed the injury "the basket ball foot".

Subtalar dislocation involves the talocalcaneal and talonavicular joints, with the tibiotalar and calcaneocuboid joints remaining intact $[5,6]$. There are four types of 


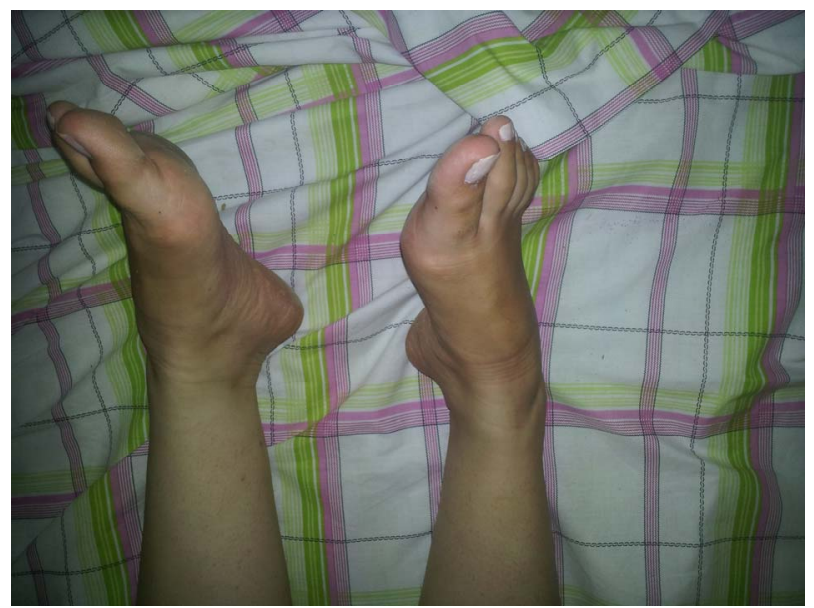

(a)

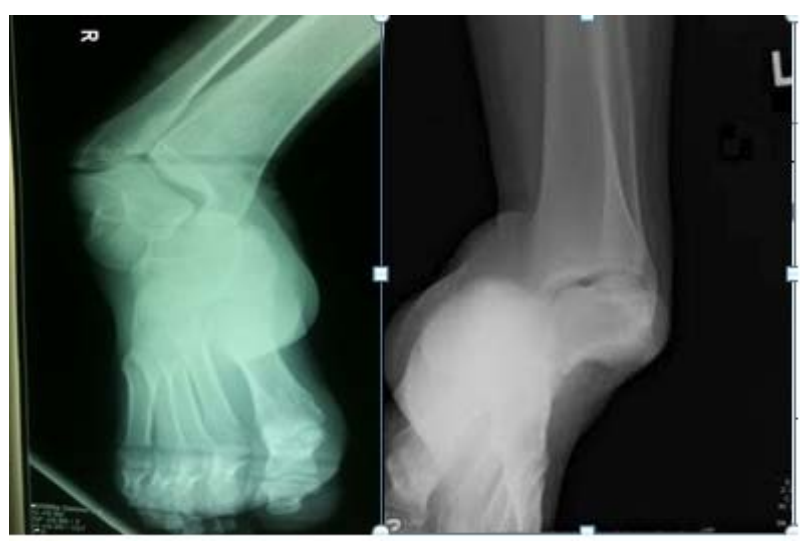

(b)

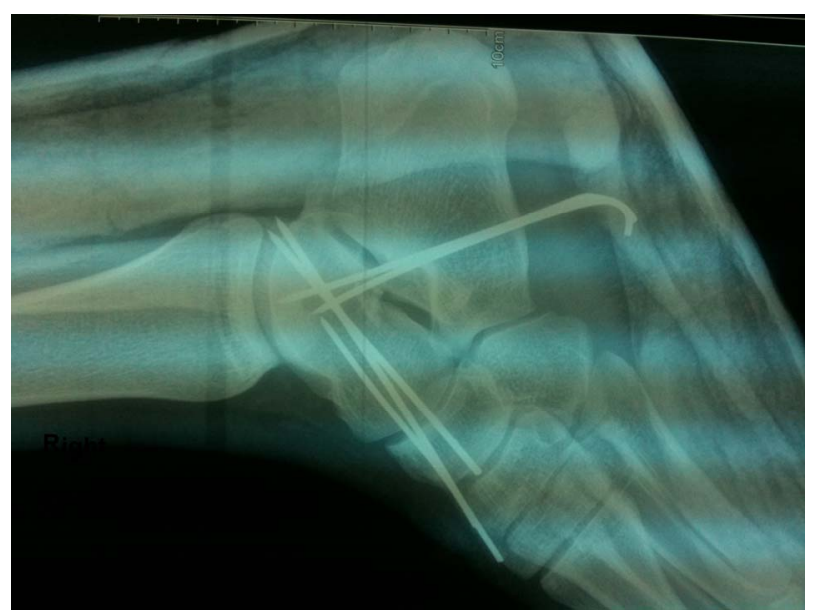

(c)

Figure 1. (a) Clinical examination showing bilateral deformity of both ankles. (b) Radiography of both ankles showing a subtalar dislocation before surgery. (c) Radiography of right ankle after surgery.

subtalar dislocation: medial, lateral,anterior and posterior. Medial dislocation is the mostcommon type. These injuries occur due to high-energytrauma. Closed reduction and immobilization is a common application for the treatment

\section{[7].}

Various factors adversely affect outcome including type of dislocation (lateral/medial, open/closed), severity of the injury and associated fractures [8]. Immediate treatment is necessary to reduce the incidence of early soft-tissue and vascular complications and poor long-term outcomes due topost-traumatic arthritis, talus necrosis and subtalar joint stiffness.

Our patient had joint laxity, especially of the largejoints and normal skin. Type-Ill and type-VII EhlersDanlos syndrome is characterized by joint laxity and minimumor absent skin findings. Type-Ill Ehlers-Danlos syndrome has autosornal-dorninant inheritance. Since neither of the patient's parents had the disease, it is unlikely that she had type-Ill Ehlers-Danlos syndrome. Therefore, type-VII Ehlers-Danlos syndrome, which has autosomal recessive inheritance, would be the most likely diagnosis in this patient and the probable reason for the bilateral subtalar dislocation.

\section{Conclusion}

Ankle disk (a "wobble board") training has been found not only to improve the feeling of giving way as well as postural control and pronator muscle strength [9], but also to reduce the incidence of ankle sprains [10]. The authors suggest that preventive measures such as ankle disk training should be obligatory in athletes suffering from functional instability of the ankle.

\section{REFERENCES}

[1] D. Caine, B. Cochrane, C. Caine, et al., "An Epidemiologic Investigation of Injuries Affecting Young Competitive Female Gymnasts,” The American Journal of Sports Medicine, Vol. 17, No. 6, 1989, pp. 811-820. http://dx.doi.org/10.1177/036354658901700616

[2] D. A. Mattingiy and P. J. Stern, "Bilateral Subtalar Dislocations,” A Case Report, Clinical Orthopaedics, Vol. 177, 1983, pp. 122-124.

[3] T. Janssen and J. Kopta, "Bilateral Recurrent Subtalar Dislocation,” The Journal of Bone \& Joint Surgery, Vol. 195, No. 67A, pp. 1432-1433.

[4] G. Y. El Khoury and D. H. Yoursef Zadek, "Subtalar Dislocation,” Skeletal Radiology, Vol. 8, No. 2, 1982, pp. 99103.

[5] S. A. Grantham, "Medial Subtalar Dislocation: Five Cases with a Common Etiology," Journal of Trauma, Vol. 4, No. 6, 1964, pp. 845-849. http://dx.doi.org/10.1097/00005373-196411000-00012

[6] X. Conesa, V. Barro, D. Barastegui, L. Batalla, J. Tomás and V. Molero, "Lateral Subtalar Dislocation Associated with Bimalleolarfracture: Case Report and Literature Review," Journal of Foot and Ankle Surgery, Vol. 50, No. 5, 2011, pp. 612-615.

http://dx.doi.org/10.1053/j.jfas.2011.04.034 
[7] L. De Palma, A. Santucci, M. Marinelli, E. Borgogno and A. Catalani, "Clinical Outcome of Closed Isolated Subtalar Dislocations," Archives of Orthopaedic and Trauma Surgery, Vol. 128, No. 6, 2008, pp. 593-598. http://dx.doi.org/10.1007/s00402-007-0459-8

[8] L. Camarda, U. Martorana and M. D’Arienzo, "Posterior Subtalar Dislocation,” Orthopedics, Vol. 32, No. 7, 2009, p. 530. http://dx.doi.org/10.3928/01477447-20090527-25
[9] H. Tropp, "Functional Instability of the Ankle Joint,” Linkoping University Medical Dissertations, No. 202, 1985.

[10] H. Tropp, C. Askling and J. Gilquist, "Prevention of Ankle Sprains," The American Journal of Sports Medicine, Vol. 13, No. 4, 1985, pp. 259-262. 